\title{
Comercios del deseo y políticas de la imagen. Fotografía mexicana 1890-1940
}

Commerce of desire and image politics. Mexican photography (1890-1940)

\author{
MARIAFERNANDA FERNÁNDEZ ROMERO* \\ México
}

\begin{abstract}
MARISELA BERENICE PARDO HERNÁNDEZ**
Universidad Iberoamericana

México

* mariafernanda.fernandez.romero@gmail.com

(iD) http://orcid.org/0000-0001-557-435X

** pardo.berenice@gmail.com
\end{abstract}

(iD) http://orcid.org/0000-0003-2365-5969

d. https://doi.org/10.52948/ds.v3i2.419

Artículo de investigación

Recepción: 20 de noviembre de 2020

Aprobación: 23 de septiembre de 2021

Cómo citar este artículo:

Fernández Romero, M., y Pardo Hernández, M. (2021). Comercios del deseo y políticas de la imagen. Fotografía mexicana 1890-1940. Designio, 3(2), 62-85. 


\section{Resumen}

Partiendo de la pregunta sobre el origen y destino de fotografías eróticas en México entre 1863 y 1940, en acervos privados; hemos ampliado el objeto de estudio a los archivos públicos que contienen fotografías de trabajadoras sexuales para registros médicos y policiacos. Este artículo consta de dos propuestas principales: en primer lugar, acuñar un término para el conjunto documental de fotografías ligadas a la prostitución femenina como parte de un fenómeno mucho más extenso y complejo al que llamaremos "comercios del deseo", que incluye la producción fotográfica y las diferentes formas de comercialización. En segundo lugar, proponemos una metodología para reclasificar acervos públicos de fotografías catalogadas bajo el criterio de "prostitución", que evite juicios morales y ayude a los investigadores a reescribir una memoria histórica con perspectiva de género.

Palabras clave: trabajo sexual; prostitución; fotografía; catalogación; fotografía erótica; control sanitario; comercios del deseo.

\section{Abstract}

We started our research examining the creation and distribution of erotic photography in Mexico between 1863 and 1940; mostly from private collections. Our investigation extended to an analysis of public archives that include pictures of sex workers for medical and police records. This proposal has two primary purposes: first, to regroup photographs of women classified under the term "prostitution" into a more complex and extended category that will call "markets of desire," which encompasses the photographic production and the different circuits of distribution. Second, we suggest a method to reclassify photos labelled as "prostitution" in the national photographic archives (SINAFO) that reduces moral judgements and could help researchers rewrite a historical memory from a gender perspective.

Keywords: sexual work; prostitution; photography; cataloging; erotic photography; sanitary control; desire trade. 


\section{Introducción}

Marginalización, discriminación y maltrato físico son solo algunas manifestaciones de los estigmas. La repetición de estas acciones y conductas punitivas provoca una internalización de la violencia que degrada la imagen propia (Hallgrímsdóttir et al., 2008). En México las trabajadoras sexuales viven día a día los estigmas inherentes a su profesión, de cuya precaria situación existe un registro desde los siglos del virreinato novohispano. Sin embargo, también encontramos imágenes y textos que rompen con supuestos y formulaciones de orden moral sobre la prostitución y la sexualidad ya entrado el siglo XIX.1

En el presente texto estudiaremos algunas imágenes relacionadas con el comercio sexual en México desde una perspectiva crítica, para entender cómo funcionaba. Decidimos acotar nuestra investigación con ejemplos puntuales entre la segunda mitad del siglo XIX y la primera mitad del XX. Esta selección responde, en primer lugar, a las innovaciones que trajo el imperio de Maximiliano de Habsburgo (1863-1867) en relación con el uso de la tecnología fotográfica aplicada al desarrollo de políticas de vigilancia moral y de salud pública. Posteriormente, las políticas higienistas implementadas durante la administración porfirista y las consecuentes vicisitudes del México posrevolucionario complejizaron las prácticas del comercio sexual, aunado al auge de la modernización del país y su paradójica pauperización en el campo, lo que atrajo familias enteras a las capitales económicas del territorio. Asimismo, analizaremos piezas de fotografía erótica que dan a conocer un funcionamiento más complejo y diverso del comercio sexual finisecular.

Nuestra investigación comenzó casi una década atrás al revisar archivos jurídicos, de salud pública y colecciones fotográficas privadas. Con este material hemos examinado aspectos formales y técnicos propios de las fotografías, para ampliar la manera de entender los oficios que en él se inscriben. La primera parte consiste en estudiar las representaciones fotográficas de la sexualidad sujetas a dos funciones principales: la erótica y la del control sanitario. En la segunda, observaremos cómo la clasificación actual de esas representaciones reduce el comercio sexual, únicamente, a la práctica de la prostitución. La última parte consiste en un ejercicio de reflexión y clasificación archivística de colecciones

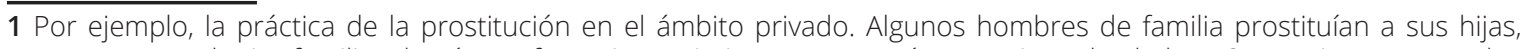
esposas o a cualquier familiar de género femenino; asimismo, era común que niñas desde los 12 años ingresaran a los burdeles (ver Lavrín, 2005, pp. 489-517). 
fotográficas donde presentamos elementos que incluyen aspectos inmersos en el comercio sexual y evita catalogaciones engañosas, discriminatorias y con un claro sesgo de género.

\section{Los cuerpos del trabajo sexual}

\section{El cuerpo de la trabajadora sexual en el imaginario erótico.}

Las imágenes reunidas en La casa de citas en el barrio galante (1992) conforman una serie fotográfica de mujeres desnudas y semidesnudas que, según el autor, trabajaban en burdeles de México entre 1900 y 1920 (Vargas, 1992, p. XVII). Los escenarios, las poses, el maquillaje y el vestuario -así como la ausencia de él- revelan montajes elaborados que adentran al espectador a un mundo exótico, "natural" y voluptuoso.

Figura 1. Fotografías estereoscópicas de la Colección de Ava Vargas

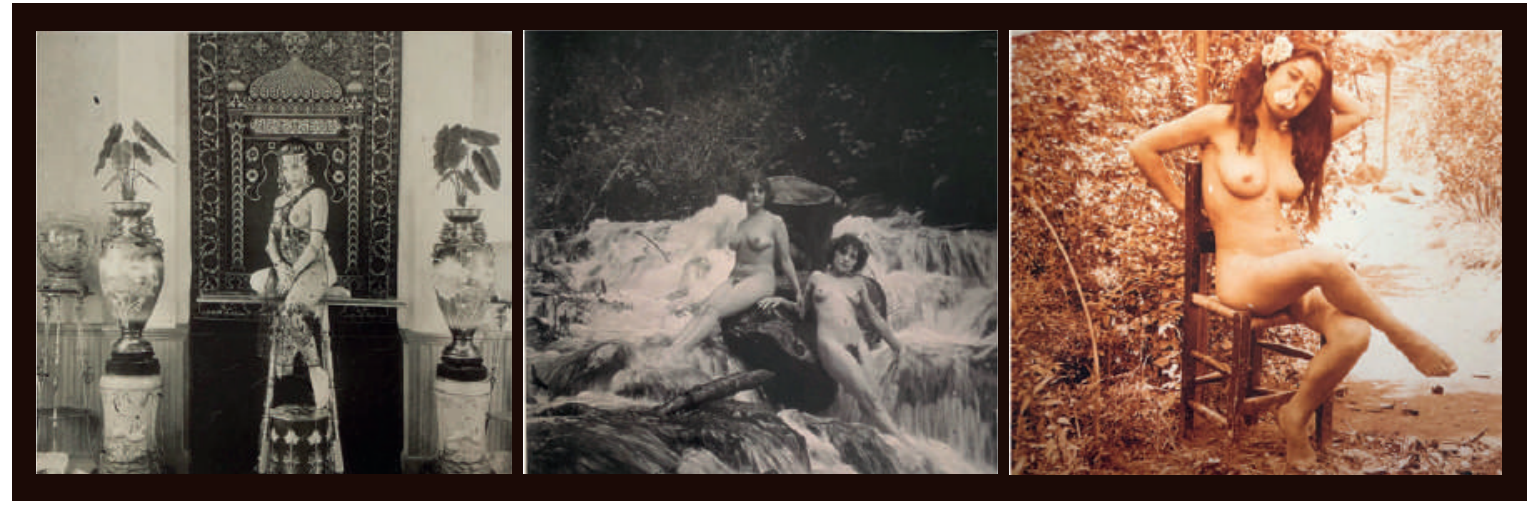

Fuente: JBG, ca., La casa de citas en el barrio galante, 1922.

Poco se sabe del autor de estas series. Miguel Ángel Morales (2010) ha propuesto que la identidad de quien firmó estas fotografías estereoscópicas, y firmaba como JBG o JB, se trata del dueño de un estudio de cine fotográfico, de apellido Berriozábal, quien a finales de los años 1920 se ubicaba en el centro de la Ciudad de México (p. 76). Sin embargo, los elementos que aporta para esta identificación son insuficientes, por lo que no lo consideramos como una conjetura concluyente, pero sí como un tema a investigar por lo que respecta a la práctica fotográfica comercial y a los agentes que confluyen en ella como parte de una 
compleja red de comercio cuyo eje gira en torno a la erotización del comercio o al comercio del deseo, el cual retomaremos en una investigación posterior.

Por otra parte, en cuanto a la sede de las tomas fotográficas, Alfonso Sánchez Arteche identificó al personaje de un retrato que se encuentra en una de las imágenes. Se trata de Manuel Medina Garduño, gobernador del Estado de México de 1911 a 1913. Asimismo, Sánchez Arteche reconoce tres lugares donde se pudieron haber llevado a cabo las sesiones fotográficas: la hacienda San Pedro Tejalpa, propiedad de Medina Garduño; la Villa Ferrat y la hacienda Atenco, todas en el Estado de México.3

Supone también que la fecha de estas fotografías sería alrededor de 1922. Con base en los testimonios de dos cronistas, Sánchez Arteche (2002) relata que Fernando Medina, hijo de Manuel, produjo una película romántica sobre la Revolución Mexicana (p. 42). El investigador piensa que algunas de las actrices pudieron haber sido las modelos que posaron para la lente de JBG. Sin embargo, no hay evidencias que proporcionen más información sobre la producción del filme -ahora perdido- para corroborar la contratación del estudio de JBG/"Berriozábal" durante el rodaje.

A pesar de la escasa información, aquéllos que las han estudiado concuerdan que la teoría de Vargas -quien supone que el lugar es un burdel- es incorrecta. Por ello, pensar que las mujeres retratadas son, indudablemente, prostitutas es una afirmación sesgada por prejuicios morales; valoraciones que, como veremos más adelante, serán la base para la clasificación de archivos del Sistema Nacional de Fototecas de México. La pregunta es por qué Vargas lo juzgó así y por qué la serie ha funcionado como ejemplo del sistema prostibulario en México.

Más allá de su origen, pareciera que la intención de estas fotografías es generar fantasías sexuales cargadas de un exotismo similar al que evocan los desnudos de la pintura finisecular europea. Existe un paralelismo compositivo entre estas fotografías y obras pictóricas como Te aa no areois (1892) de Paul Gauguin (1848-1903), Ariadne (1898) o Circe ofreciendo la copa a Odiseo (1891), ambas de J. W. Waterhouse (18491917), Albaidé (1848) o Cleopatra probando venenos en prisioneros condenados (1887) de Alexandre Cabanel (1823-1889), solo por mencionar algunas.

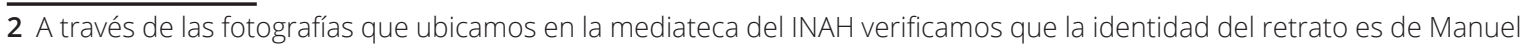
Medina Garduño. El exgobernador del Edo de México aparece en tres (3) fotografías de la Colección Archivo Casasola (Id. de catálogo 21443 y 36297).

3 Para la identificación de los lugares queremos agradecerle a nuestra colega Jimena Pastor, quien nos ha aportado fotografías y datos de los lugares que Sánchez Arteche menciona como probables locaciones. Sin embargo, no hemos corroborado la suposición del investigador, pues el acceso a los lugares es restringido y la decoración de los interiores ha cambiado. 
No podemos afirmar que el autor tuviese como referencia estas piezas en específico, sin embargo, al examinar el contexto mexicano de la época no resulta improbable pensar que estas obras sirviesen de inspiración. Amplia es la literatura que traza las conexiones artísticas entre México y Europa desde la segunda mitad del XIX hasta la Revolución. El intercambio de artistas era común: maestros llegaban del viejo continente para impartir clases en la Academia de San Carlos; si bien desde el siglo XVIII todavía bajo su adscripción real, el auge del intercambio académico se dio gracias al impulso que le dio el polémico presidente Antonio López de Santa Anna, desde la primera mitad del siglo XIX. Por otra parte era también casi una tradición que los pupilos mexicanos estudiasen bellas artes en Europa, por lo que las referencias eurocéntricas en la estética de la fotografía mexicana eran prácticamente la norma. ${ }^{4}$ No obstante, se podría considerar que algunos fotógrafos, como el caso de Romualdo García Torres, desde su estudio en el Bajío, o Juan Crisóstomo Méndez, desarrollan estilos propios, personales, inmersos en un universo íntimo lleno de imaginación y creatividad que pone en evidencia no solo sus referencias visuales, sino sus deseos.

Además de la similitud formal entre estas imágenes, queremos subrayar las narrativas que rodean el mito de la "mujer fatal" finisecular en la pintura y cómo se vinculan con las representaciones de la idea de la prostitución a finales del siglo XIX en la fotografía. La femme fatale es aquella que seduce al hombre hasta destruirlo y su poder recae en la belleza irresistible (Huvenne y van Twits, 2002, p. 9). Durante el siglo XIX, los artistas crearon un imaginario que relacionaba a las mujeres fatales con figuras clásicas como ninfas, diosas e incluso personajes históricos y bíblicos como Cleopatra, Eva y María Magdalena (Ystehede y Skilbrei, 2017, p. 7). Ejercían su sexualidad insaciablemente y seducían hombres de formas agresivas hasta llevarlos a la ruina. La femme fatale adquiere poder y se emancipa a través de su potencial erótico (Bel, 2003, p. 43) que se manifiesta usualmente con fetiches como zapatos, medias, antifaces, o la desnudez reflejada a través de espejos, vidrios y ropa translúcida. Se erige, además, en contraposición de la mujer decente, constreñida al ámbito doméstico y que asume su sexualidad solo con fines reproductivos, dentro del matrimonio (Reynolds y Humble, 1993, p. 63). Como se ha estudiado profusamente, las prostitutas se asociaron con la

4 Sobre los intercambios académicos y los artistas viajeros conviene revisar Diener (1996); Lozano (1999). Para el estudio de la fotografía decimonónica, es indispensable revisar: Debroise (2005) y Casanova (2002). 
femme fatale pues ejercían su sexualidad fuera de la moral y las buenas costumbres, incluidas la vestimenta provocativa y la desnudez.

Las modelos deJBG comparten con las mujeres fatales de la pintura decimonónica la ausencia casi total de ropa y las poses; entornos que integran elementos orientalistas o "exóticos" y una intención de seducir al espectador, pues todas miran a la cámara, confrontando miradas, asumiendo una participación activa. Entonces, no sorprende que Vargas y aquéllos que usan estas imágenes como representaciones del sistema prostibulario en el México finisecular vinculen a las sensuales modelos con prostitutas y a las locaciones con un burdel.

Sin embargo, hay detalles que nos hacen cuestionar esta teoría. En las 87 láminas publicadas en la edición mexicana de La casa de citas identificamos 33 mujeres distintas, 13 habitaciones y 11 exteriores. Si se tratase de un burdel tendría que ser uno extraordinariamente grande, con amplias zonas al aire libre y la capacidad para albergar a un gran grupo de mujeres y sus clientes. En la extraordinaria tesis de maestría Mujeres públicas bajo el Imperio. La prostitución en la ciudad de México durante el Imperio de Maximiliano, 1864-1867, Ixchel Delgado Jordá (1998) traza un mapa de los prostíbulos y zonas de tolerancia en dicho período: las casas de citas y accesorias estaban ubicados en zonas de tolerancia y eran lugares discretos. Aún si el mapa sufre cambios a través del tiempo, pensamos que la dimensión de los burdeles y la localización en zonas restringidas no sufren grandes transformaciones (al menos hasta 1940, cuando surgen las leyes abolicionistas y desaparecen las llamadas "zonas de tolerancia").

Estas características llevan a pensar que la teoría del burdel es arquitectónica y físicamente improbable. Asimismo, la meticulosa disposición del mobiliarioy la inclusión de retratos familiares y de otras mujeres en la escenografía 5 apuntan más al encargo apuntan más al encargo de un particular. También dudamos que sean fotografías de estudio destinadas a un consumo extendido, pues las tarjetas y postales eróticas generalmente desplegaban escenas menos suntuosas. ${ }^{6}$ Estamos desarrollando la hipótesis de los encargos personales y puntuales para la creación de estas series,

5 En varias de las fotografías de la serie se aprecian retratos de mujeres como parte de las escenografías. Se pueden identificar locaciones, vestimentas y mobiliario similares. Considerando el tiempo de tomar y revelar las fotos, podríamos pensar que el autor de la serie la realizó durante un período de tiempo considerable y probablemente en más de una sesión.

6 Miguel Ángel Morales publica en la revista Alquimia en el 2010 un estudio de las postales y tarjetas de visitas eróticas que se distribuían y estaban a la venta masivamente. Las imágenes se distancian de las de JBG, en tanto que muestran fondos lisos, de colores claros; las mujeres posan desnudas y frecuentemente no ven a la cámara. La mayoría están desnudas o llevan atuendos reveladores que las caracterizan como mucamas francesas, princesas aztecas, o ninfas. Salvador Salas Zamudio (2011, pp. 152-182) realiza un estudio similar sobre los estudios fotográficos que producían postales eróticas. 
como parte de la afición de individuos letrados y comúnmente acaudalados; la logística, la producción y la disposición de espacios para la creación de fotografías eróticas de esta índole requiere de pocos recursos tanto económicos, como humanos. También investigamos el componente lucrativo de su producción.

Respecto a las supuestas prostitutas, ¿podrían ser solo mujeres que posaron para una colección privada?, ¿podrían ser cabareteras o las actrices de la película de Fernando Medina, como lo sugiere Sánchez Arteche? Sin tener más información es imposible conocer la identidad de las modelos, pero no podemos afirmar que son prostitutas, como se ha sugerido comúnmente y, más aún, como se tienen registradas fotografías similares en catálogos públicos y privados, incluyendo el del Sistema Nacional de Fototecas de México. Aún si no hay pistas de ellas, las fotografías revelan algo de sus espectadores: están pensadas para recrear la mirada masculina y estimular la imaginación burguesa y educada, cuya mirada detecta los guiños de composiciones artísticas europeas y la presencia de ciertos objetos ornamentales.

Con base en lo anterior no debemos aceptar sin cuestionamientos el hecho de que las fotografías eróticas finiseculares sean un corpus de representación de la prostitución, específicamente las firmadas por "JBG". La calidad superior de las imágenes, el formato y sus características formales evidencian la existencia de la fotografía erótica cuidadosamente producida, que se diferencia de la fotografía de retrato social en sus elementos económicos, socioculturales y materiales de la pornografía y la prostitución.

Asimismo, la falta de documentación en torno a estas fotografías, que Ava Vargas encontró por casualidad, revela desde nuestra perspectiva una necesidad de ocultar el comercio sexual. Es decir, es la ausencia y no la presencia de información la que destaca la cualidad de este tipo de comercio. Aun si el contenido de las fotografías es "explícito", la información que tenemos de ellas no lo es. Ya sea por la falta de datos externos a las fotografías (como en este caso); o bien, por el afán de "higienizar" y ocultar cualquier rastro del comercio sexual, como veremos en la siguiente parte; producen lagunas en las investigaciones en torno a este.

7 Ver Córdova (2003, pp. 37-39; 2005, pp. 7-16). 


\section{El cuerpo de las trabajadoras sexuales en el contexto médico-sanitario}

Desde 1864 hasta 1940 la Policía Sanitaria se encargó de salvaguardar la salud pública.8 Según el Reglamento de Mujeres (1867), la división de la Inspección Antivenérea vigilaba la operación de burdeles y el comercio sexual en las calles; tenía la tarea de expedir las licencias que acreditaran el ejercicio de la prostitución y llevar un registro (Fondo Salud Pública, serie Inspección Antivenérea, caja 1, expediente 1). Uno de ellos, que resalta por el material documental se encuentra en el fondo reservado de la Biblioteca Miguel Lerdo de Tejada, de la Secretaría de Hacienda y Crédito Público.

El registro no solo muestra los datos personales y del oficio de las trabajadoras sexuales, sino que incluye retratos fotográficos. Esta práctica era común desde mediados del siglo XIX y se extendió para todas las actividades criminales. En dichos retratos las mujeres miran de frente, su semblante es serio, a veces transmiten un sentimiento de inconformidad, de altivez o desafío. En ocasiones, desfiguran su rostro con un movimiento para evitar su identificación. Las indumentarias varían: usan desde vestidos profusamente decorados, hasta huipiles con rebozo, según la clase a la que pertenecían. Algunas mujeres portan sombreros o mantillas; otras el pelo recogido. El fondo es claro, en la mayoría, removiendo cualquier tipo de indicio arquitectónico o contexto que pudiera dar cuenta del oficio que ejercían. Encontramos varios formatos: retratos ovalados y rectángulos; retratos de busto, medio cuerpo o cuerpo completo. ${ }^{9}$

A diferencia de la colección de Ava Vargas, donde no hay un solo dato de la ubicación y la identidad de las mujeres; las imágenes para el control sanitario van acompañadas de una descripción; según el Reg/amento de Mujeres Públicas (1878) debe contener "Ios siguientes pormenores: el nombre y apellido de la mujer, su edad, filiación, lugar de nacimiento, estado, causas de su determinación, nota de su estado sanitario, y por último su cuota corriente de impuesto".

8 El Nuevo código sanitario de los Estados Unidos Mexicanos, escrito por el Lic. Francisco Vázquez Pérez, jefe del Departamento Jurídico del Departamento de Salubridad, ya en 1935 todavía considera como legal la prostitución y se refiere así, en el artículo 172, respecto a la regulación de su práctica "El Departamento fijará para el Distrito Federal, los requisitos que deberán llenar y las condiciones higiénicas y los servicios médicos de que deberán estar dotados: las zonas de tolerancia, las casas de asignación de citas, hoteles y en general todos los locales en que se ejerza el comercio sexual. El establecimiento de las zonas estará sujeto a las prescripciones del reglamento respectivo" (p. 47).

9 Catálogo de prostitutas del Gobernador J.J. Baz, 1868, Fondo Reservado, Biblioteca Miguel Lerdo de Tejada, Secretaría de Hacienda y Crédito Público, México. 
De forma paradójica, aún si sabemos la identidad y el oficio de estas mujeres, la fotografía pretende borrar todo tipo de lenguaje visual que pudiera sugerir una dimensión sexual o erótica del cuerpo de la prostituta. Es decir, sin la información personal que resguardan estos libros, únicamente observamos fotografías de mujeres que podríamos clasificar con criterios de orden económico por su vestimenta y origen étnico.

La forma responde al modelo higienista que se implementó para regular la prostitución. Desde el mandato de Maximiliano de Habsburgo (1863-1867), hasta el de Porfirio Díaz (1876-1911), el modelo regulatorio que se implementó en México se inspiró en el del higienista francés A. J. B. Parent Duchatelet (París, 17901835). Este dedicó varios años al estudio de la prostitución en París y sus efectos sociales. En 1836, aparece de forma póstuma un detallado análisis, intitulado De la prostitution dans la Ville de Paris. Su dedicación a la salud pública lo condujo a escribir libros sobre sistemas de drenaje, desechos y epidemias, enfocados en la urbanización y la modernización del sistema de salud.

La innovación de su acercamiento a la prostitución fue el enfoque sanitario. Enfrentar la epidemia de sífilis de aquella época como un problema de salud pública fue un gran acierto que le ganó reconocimiento mundial. Sin embargo, la noción de suciedad y enfermedad se extendió a la definición de las mujeres inscritas dentro del comercio sexual. Su intención no solo era sanar cuerpos, sino una sociedad enferma a causa de la prostitución. El carácter científico y antropológico de su investigación le confirió una cualidad de verdad absoluta a su estudio, pues frecuentó burdeles, observó las calles, presenció análisis médicos y entrevistó tanto a autoridades como a mujeres públicas (Bell, 1994, p. 49).

En el prefacio de la edición de 1857, el doctor Fr. Leuret fusiona conceptos moralesy médicos para concebir la prostitución como un "mal necesario", imposible de erradicar, el cual se debe "limpiar" (Parent Duchatelet, 1857, p. XIX). Tacha los burdeles y las prostitutas de inmorales, despreciables, infames y sucios; algo que se debe ocultar (Parent Duchatelet, 1857, p. XIX). Al mismo tiempo se requieren para guardar un orden social y moral, donde las mujeres decentes solo tienen sexo con fines reproductivos. Para enfatizar el carácter ignominioso de la prostitución describe a Parent Duchatelet como un héroe incorruptible, proveniente de una familia inmaculada, virtuosa y honorable; el único capaz de limpiar el mal sanitario y social que provoca la prostitución. Además, no escapa a la tentación de hacer analogías entre dicho oficio y el drenaje como origen de la podredumbre. 
Este discurso, que ubica cloacas y prostitutas en el mismo nivel, tuvo serias repercusiones en la manera que trataban -y aún tratamos- a estas mujeres: no solo deben estar contenidas, ocultas y controladas, sino que deben ser consideradas como desechos (Ystehede y Skilbrei, 2017, p.12).

Para dar cuenta de la extensión del estigma que sufrían las trabajadoras sexuales, nos gustaría citar algunos ejemplos de los reportes que encontramos en el Archivo Histórico de la Secretaría de Salud (AHSS). En una nota periodística publicada en 1881, por la Secretaría del Estado y del Despacho de Gobernación, resalta que si bien el Hospital Morelos ${ }^{10}$ se encontraba en buenas condiciones, la sala provisional instalada en comedor era insalubre (Fondo Beneficencia Pública, serie Hospital Morelos, legajo 2, expedientes 18-37). La modificación del comedor respondía a la falta de espacios destinados para atender a las enfermas. En varios expedientes de este legajo, el director narra que el número de prostitutas clandestinas aumentaba con las redadas y esto tuvo como consecuencia un número insuficiente de camas, equipo y material para atenderlas. Contesta, además, a una queja del inspector sobre las condiciones de las salas de enfermas: las mujeres estaban en el suelo en petates, sin cobijas ni mantas porque el hospital no se daba abasto. La capacidad de 180 pacientes casi se duplicaba.

En otro documento de 1892, el inspector de sanidad presenta una queja porque el hospital recibe enfermas sin que la inspección tenga conocimiento de ello. En la aclaración ante la denuncia, el director del nosocomio afirma que las mujeres no registradas son ancianas que se curan de enfermedades de la cintura, otras accidentadas de la piel y algunas afectadas por la sífilis que "se encuentran casadas, cuyos maridos las han enfermado, y que, confiando en la discreción y especialidad del hospital, solicitan cama para ser atendidas; lo mismo sucede con domésticas que las familias mandan, sin que estas, deban considerarse como prostitutas" (Fondo Beneficencia Pública, serie Hospital Morelos, legajo 2, expediente 31). Esta falsa identificación de prostitutas se extiende a otros casos, en los que la corrupción y una aplicación negligente de la ley, coacciona a las mujeres para asumirse como prostitutas:

10 Este hospital atendía a las mujeres que contrajeran sífilis y otras enfermedades venéreas, desde 1868, cuando aún se llamaba San Juan de Dios. En 1875, cambia de nombre a Hospital Morelos tras la expulsión de las órdenes religiosas en México. Cabe mencionar que la mediateca del INAH cuenta un acervo de fotografías de mujeres a las que atendían en dicho hospital, sobre el cual también hemos reunido material representativo con fines de investigación. 
Los agentes de Sanidad son la causa del aumento de la prostitución en México, pues para hacerse aparecer como fieles guardianes de su deber, conducen a la Inspección de Sanidad a centenares de mujeres, que acaso nunca han pensado en la prostitución, y que con su infame proceder las obligan a seguir esa odiosa carrera, con mengua indudablemente de sus familias y con perjuicio de la sociedad en que vivimos, que cada vez se hace más insoportable por el aumento de la prostitución. ${ }^{11}$

Las razones por las que los inspectores identificaban como prostitutas a mujeres que no lo eran podrían ser muchas: ¿iban solas por la noche?, ¿eran pobres y estaban en el lugar equivocado? De cualquier manera, la criminalización del comercio sexual y el desprecio hacia quien lo ejerce siguen tan arraigados en la sociedad que ha penetrado las formas de catalogar los acervos fotográficos, cuestión que abordaremos en la parte final de este artículo.

Un último ejemplo de violencia de género -resultado de las malas prácticas médicas y una incapacidad para reconocer a las trabajadoras sexuales como seres humanos- lo encontramos en las Memorias de la inspección sanitaria, escritas por el doctor Alfaro, entre 1868 y 1875 (como se citó en Núñez, 2001, pp. 56-57). Este hace evidente la falta de higiene -y de compasión- para tratar a las enfermas:

Aún sin resolver la cuestión de la dualidad o la unicidad delveneno sifilítico, los hechos manifiestan claramente que el chancro duro, y todos los accidentes llamados secundarios son eficaz y fatalmente contagiosos [...] teniendo en cuenta la facilidad y gravedad del contagio no es profiláctico secuestrar a las sifilíticas junto a las otras. Deberíamos separarlas para poder curarlas con otros instrumentos, al practicar las curaciones diarias, se deberá marcar la ropa y utensilios, cucharas, jeringas, espejos, para no contagiar a las otras. De otro modo, como están las cosas, es probable que se infecte con pus sifilítico a mujeres afectadas con otra cosa. [...] Lo que sucede en los hospitales es que después de curar un chancroduro se cura otra cosa con las mismas pinzas, pues en la sección venérea se hayan mezcladas las que tienen sífilis con las que no la tienen. De 93 casos de hospitalizadas, solo 20 o 21 son de sífilis clara.

11 La gaceta de México, año III, n. 18, jueves 31 de julio de 1884, México, D. F. Los operativos antitrata son aún un tema de debate, pues las trabajadoras sexuales que ejercen voluntariamente e incluso empleados de centros nocturnos son detenidos en las redadas por delito de trata. Esto se debe a una vaga definición entre trabajo y explotación sexuales. Investigadoras como Marta Lamas, Elizabeth Bernstein (2014) y el colectivo Glamsex han abordado el tema sobre la criminalización del trabajo sexual, desde el feminismo interseccional. 
Así, vemos que el estigma que carga el cuerpo de la trabajadora sexual como fuente de contagio y vileza es, en parte, una creación del quehacer médico y social del siglo XIX. Desafortunadamente, la fuerza de dicho estigma es todavía tan grande que algunas trabajadoras sexuales asimilan las enfermedades venéreas no como un riesgo de su oficio, sino como su destino (Lamas, 2017, pp. 64-66). ${ }^{12}$

Como bien lo indica Shannon Bell (1994), el comercio sexual en tanto que campo discursivo ha tenido un lugar marginal en el mundo de los saberes occidentales. El cuerpo de las personas que lo practican y su clasificación como algo enfermo, sucio, criminal, inmoral, así como la dicotomía entre las mujeres "decentes" y las "putas", no favorecen un estudio complejo y crítico de las prácticas sexuales, ni su comercio.

Podemos identificar que tanto las imágenes eróticas como las de registro médico están cruzadas por estereotipos y lagunas que requieren ser estudiadas con ayuda de otros documentos y disciplinas. Si bien son documentos de primera mano que nos ofrecen información histórica, las lecturas que les damos hoy están cargadas de antiguos estigmas. En la siguiente parte, propondremos una metodología para catalogar este tipo de imágenes desde una perspectiva crítica y de género.

\section{De estigmas y archivos}

Las implicaciones de cada imagen extienden el tema del trabajo sexual hacia los límites de otras disciplinas como la antropología visual, pues las fotografías que mostraban mayor información en las escenas representadas se insertaban en un contexto específico. Los aspectos económico, político y social convierten a la imagen en un documento sin palabras, cuyo contenido visual resulta en una fuente de información de primera mano, al describir las escenas sin aislar los cuerpos de su entorno.

De esta manera, se fue ampliando el objeto de estudio. La propia descripción de las fotografías llevaba a formular preguntas que derivan en la cuestión sobre la práctica del comercio sexual como un oficio presente en México a lo largo de su

12 Es necesario mencionar que la clasificación de las fotografías de las internas del Hospital Morelos asocia palabras como "enfermos", "mujeres", "enfermos mentales", "higiene sexual" y "prostitución". De acuerdo con nuestra tesis, estas catalogaciones son problemáticas en tanto que estigmatizan el ejercicio del comercio sexual. 
historia y cuyo registro visual documenta aspectos de la vida cotidiana en nuestro país; así como el paso del tiempo a través de las políticas de salud pública, los códigos gestuales y, por supuesto, la presencia activa de mujeres en la vida pública, su (in)visibilidad y las interacciones económicas que, desde su oficio, formaron parte de la dinámica social.

Al día de hoy hemos ampliado el objeto de estudio al material que forma parte de los acervos del Sistema Nacional de Fototecas del Instituto Nacional de Antropología e Historia (INAH), específicamente las imágenes que se encuentran catalogadas como "retrato" y "prostitución". Entre estas se pueden encontrar fotografías realizadas en hospitales para sifilíticas (Hospital Morelos) e imágenes documentales en las que aparecen "mujeres públicas", posando y socializando con otras mujeres o con hombres, en un amplio espectro de contextos que hacen problemática su identificación como parte del ámbito de la prostitución. Todo esto, sin dejar de lado las imágenes de registros de prostitutas y las imágenes eróticas que no necesariamente aparecen bajo esa clasificación. Sin embargo, la constante en los ámbitos mencionados es la presencia de las mujeres y su sexualidad, ya sea indicada en el registro de sus fichas en catálogos públicos, en el mismo objeto, o bien, a través de su propio cuerpo.

Bajo la premisa de que toda persona es una persona histórica $y$, en consecuencia, toda fuente es una fuente histórica (Lukacs, 2011, p. 32); esta propuesta puntual consiste en que toda imagen y, en este caso específico, las fotografías dentro de un acervo documental, pueden ser consideradas como fuentes de información para historiar la identidad sociopolítica de una nación en un contexto específico, por ser en sí mismas y en su materialidad, un documento.

Por otra parte, dicho documento -que ya supone la existencia de datos que lo sitúan en un contexto específico por su producción y su función- contiene una imagen que, a diferencia de la pintura, muestra la representación de un objeto, un sujeto y un espacio que existieron en un momento específico. La interacción de estos elementos en la escena y la elección de su composición son en sí mismos temas de estudio, pero la descripción individual de cada uno, así como la descripción general de una serie de imágenes son acciones que implican un juicio por parte del observador, pues la propia elección de palabras revelará la postura de este frente al objeto de estudio. Sin embargo, este proceso debe ser revisado; existe una responsabilidad inherente en el acto de describir y clasificar en el que la autorreflexión sobre la posición desde la que se realiza este acto es 
fundamental para comprender qué estado guardan las fotografías dentro de una tipología en los archivos y por qué. Ejemplo de ello son los resultados que arroja el buscador del catálogo en línea de la Fototeca Nacional, y de la mediateca del INAH cuando se ingresa la palabra "prostituta", así como la descripción de cada imagen en sus respectivas fichas.

La imagen por sí misma y considerada dentro del género del retrato es un documento. Su contenido arroja información interesante que puede situar la escena en una temporalidad por la indumentaria de la mujer que la protagoniza. Por otra parte, su cuerpo es índice, en sí mismo, de un lenguaje que se puede decodificar a través de sus gestos y de su postura. En cuanto al espacio, la arquitectura y sus elementos, aunque escasos, no dejan de ser información visual para el investigador. No obstante, hay que resaltar que, además de los datos que pudieran extraerse de la fotografía como documento mediante su análisis material e iconográfico, el criterio de catalogación y las palabras elegidas para su clasificación en distintos momentos de la historia sitúan al objeto no solo dentro de un contexto específico, sino a la imagen como parte de un fenómeno social, político, económico y, sobre todo, permiten analizarla como un documento que podría formar parte de un cuerpo documental más amplio en torno a la "fotografía de género".

En palabras de Rebeca Monroy Nasr (2011), la importancia de esta nueva tipología yace en el hecho de que se puede considerar como:

[Una]memoria visual que es un documento que viene a reconstruir, insertar y matizar la presencia de las mujeres que fueron parte del retrato individual y colectivo de una época. Si justo con la imagen podemos "verlas", literalmente, y rescatarlas de la invisibilidad en la que se les ha mantenido por años, se cumple uno de los propósitos de recuperar un fragmento de memoria como parte de este proyecto de Memoria social y género. (p. 205)

Los archivos fotográficos públicos cuentan con una gran cantidad de material que se puede explorar desde distintas ópticas para reunir información que permita ampliar la investigación en torno al comercio sexual. Desde sus criterios de clasificación, pasando por los códigos de gestualidad, su estética, su materialidad y la composición de escenas; las fotografías relacionadas con el ejercicio de la sexualidad en México de mediados del siglo XIX a mediados del siglo XX pueden 
producir información suficiente para considerarse "medios de conocimiento"130 documentos de primera mano para el estudio del comercio sexual, con el apoyo de otras fuentes y disciplinas que contextualicen su existencia y su función.

Las producciones culturales en torno al fenómeno del trabajo sexual en nuestro país no han sido consideradas como un objeto de estudio y fuente de datos para su análisis histórico, político, económico y social. Tampoco se ha considerado reunirlas en un solo cuerpo documental, con el objetivo de sistematizar su consulta y su estudio. Si se quisiera realizar esta tarea, hoy en día, el principal inconveniente sería que la información con la que se les ha clasificado resulta insuficiente o confusa. ${ }^{14}$

Si reuniéramos un cuerpo documental de fotografías de género que incluya fotografía erótica, pornografía, fotografía de registro sanitario y judicial y fotoperiodismo, podríamos construir una nueva metodología de análisis de aquello a lo que las autoras hemos convenido en llamar "comercios del deseo", en México de 1840 a 1950. El primer criterio de selección será la clasificación de imágenes con las etiquetas "trabajor(a) sexual", "trabajo sexual" o "comercio sexual". El segundo criterio será la presencia de mujeres u hombres cuyos gestos aludan a su dimensión sexual, o bien, que se encuentren insertos en una escena de esta índole. El tercer criterio será la clasificación de imágenes con las etiquetas "pornografía" y "erotismo" (ver cuadro comparativo de metodología sugerida).

Para ordenarlas sugerimos los siguientes criterios:

1. Dividirlas por tipologías estrictamente formales.

2. Hacer una descripción y posteriormente, un análisis iconográfico de cada una.

3. Incluir sus criterios de catalogación actual.

4. Explorar la presencia de imágenes similares, con otros criterios de catalogación en los mismos archivos.

5. Enlistar las temáticas a las que alude cada imagen para ubicar los campos de estudio que cruzan y para los que podrían funcionar como fuentes de información de primer orden.

13 "[...] Por cierto, las propias imágenes pueden considerarse como medios del conocimiento, que de otra forma se manifiestan como textos." (Belting, 2007, p. 15).

14 "Primer problema: ¿Quién es el pueblo? No es solo que se trata de muchas personas y que, por lo tanto, la cantidad de información sobre ellas pueda ser ingente (o inexacta). El problema es la calidad (y la autenticidad) de esa información, que o es fragmentaria o es inmanejable" (Lukacs, 2007, p. 35). 
6. Formular preguntas como: ¿A qué público estaba dirigida esta fotografía?; ¿a qué necesidades respondía?; ¿quién era su autor?; ¿con qué objetivo se realizó?; ¿en qué parte del sistema económico se puede insertar?; ¿de qué oferta y de qué demanda forma parte?

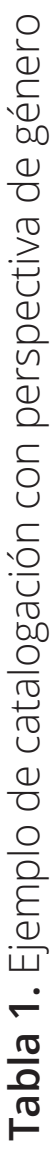

\begin{tabular}{|c|c|c|}
\hline 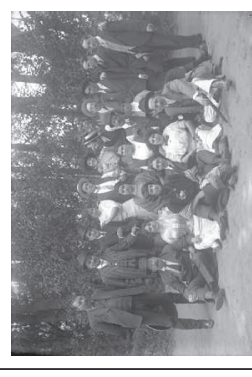 & 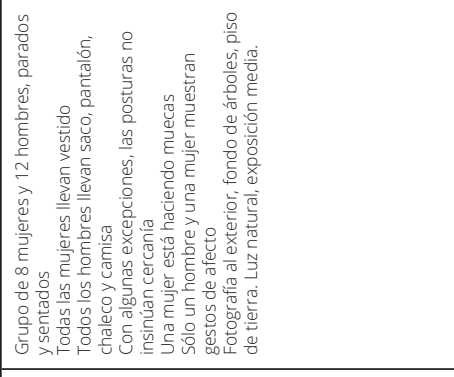 & 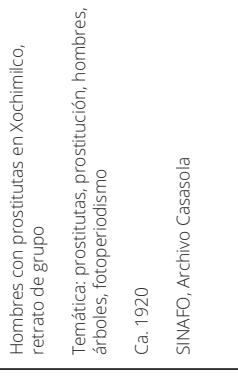 \\
\hline & 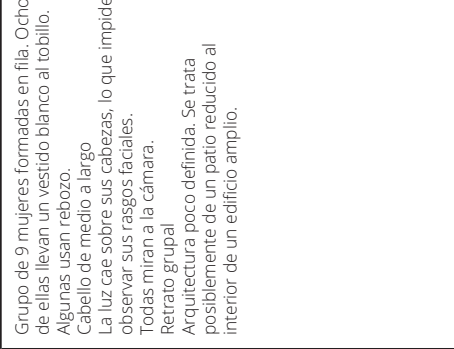 & 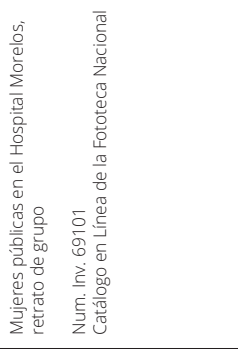 \\
\hline & 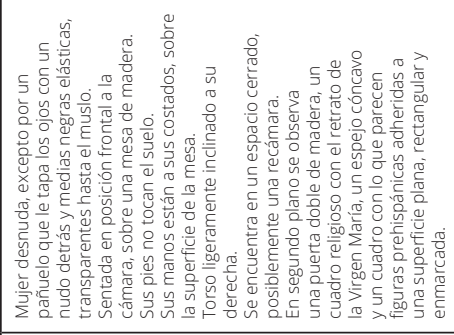 & 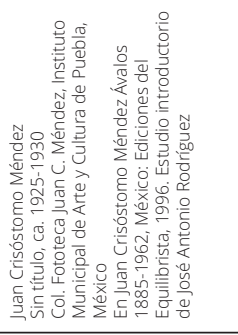 \\
\hline & 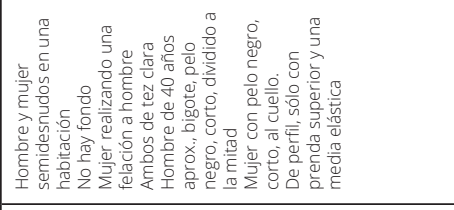 & 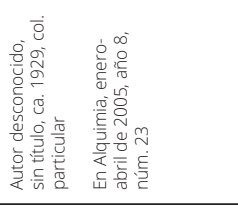 \\
\hline & 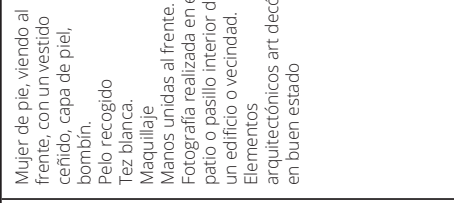 & 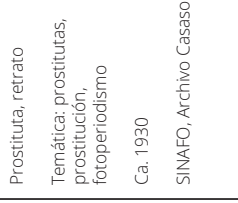 \\
\hline & 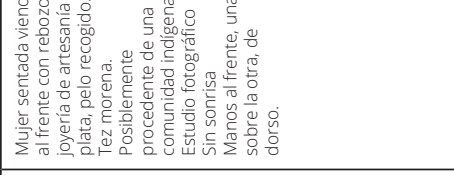 & 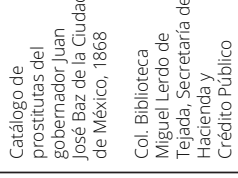 \\
\hline $\begin{array}{l}\text { 总 } \\
\text { w. } \\
\text { 量 }\end{array}$ & 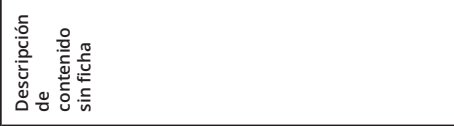 & 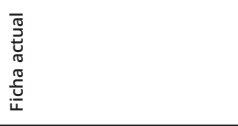 \\
\hline
\end{tabular}

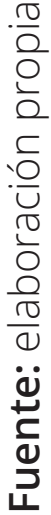


En nuestro ejemplo (tabla 1), la primera imagen pertenece al grupo de fotografías del catálogo de prostitutas del gobernador Juan José Baz, de 1868 de la Biblioteca Miguel Lerdo de Tejada. Son retratos de registro con una función muy específica, que era la de identificar, controlar y clasificar a las mujeres que ejercían la prostitución en el Estado de México, en una temporalidad acotada. En ese sentido, la fotografía como índice (Barthes, 1990, pp. 34-36) sirve también para ampliar los estudios de género y la presencia del ejercicio de sexualidades heterodoxas durante la segunda mitad del siglo XIX.

Resulta interesante que dos de los ejemplos utilizados formen parte de grupos más amplios de fotografías cuyos autores son anónimos y se encuentran actualmente en colecciones privadas. En ese sentido, estamos frente a cuestiones de consumo: ¿Se puede concluir que existía un mercado de fotografía erótica, el cual formaba parte de un sistema más complejo en el que participarían prostitutas como modelos? Es decir, ¿sería posible que detrás de esas escenas hubiera existido un sistema de comercio sexual que incluía la prostitución y la producción, venta y distribución de material erótico/pornográfico? Actualmente, no podemos respondernos esa cuestión porque, como se dijo en la primera parte del artículo, asumir que las mujeres que protagonizan la fotografía erótica de colecciones privadas son prostitutas, es incurrir en el mismo error de catalogación oficial, clasificando los sujetos con base en juicios de valor a priori.

Por otra parte, hay dos tipos de retratos grupales que, en un principio, no parecerían tener otra cosa en común. No obstante, ambos ejemplos elegidos tienen en común que sus protagonistas de género femenino ejercieron la prostitución. Sin embargo, el ámbito en el que se desenvuelven las escenas es diametralmente distinto. En la primera fotografía observamos a un grupo de mujeres, exclusivamente, en el que ninguna de ellas muestra gestos de afecto y su indumentaria parece homogénea. Esto sugiere que posiblemente estarían dentro de una institución, como lo constatan los datos de su ficha: se trata de mujeres (posiblemente pacientes, aunque no lo sabemos con certeza) en el hospital Morelos para sifilíticas.

Finalmente, en las imágenes estrictamente documentales clasificadas como dentro de la temática de "prostitución" y "fotoperiodismo", la presencia de mujeres es constante. En ellas es común observar otros actores en escena, por decirlo de forma metafórica. Estos son hombres, en su mayoría, que fungían como acompañantes de las damas y viceversa. Las escenas sugieren tertulias, 
reuniones o encuentros fortuitos en calles de la ciudad de México y otros puntos geográficos, algunas veces de noche y otras de día. En este cuerpo documental es interesante cómo la tajante división que se hizo, atribuyendo el género femenino a lo privado y al género masculino a lo público, se rompe por completo, pues todos los involucrados en estas imágenes forman parte del universo de lo público y la cultura popular en el México postrevolucionario. Cabría preguntarse si, desde esa óptica, las mujeres de las fotografías dejarían de estudiarse como sujetos femeninos.

Este método comparativo entre imágenes que tienen en común la sexualidad, pero que tipológicamente podrían formar parte de otra temática, arroja resultados interesantes porque la descripción desprovista de su clasificación actual nos permite situarnos como espectadores y ser conscientes de nuestra propia limitación como investigadores al enunciar lo que vemos de determinada forma. La simple elección de palabras determina lo que vemos y desde qué perspectiva analizaremos el objeto en cuestión, pero también nos muestra cómo fue clasificada esa imagen, poniendo de manifiesto los criterios de su tipología y la posición que ocupa en el acervo.

El análisis de este ejercicio de comparación y contraste entre imágenes permitirá producir conocimiento de la dimensión estética, política, social y económica de la historia de un fenómeno en un contexto específico de la realidad mexicana, a través de la fotografía.

\section{Conclusiones}

A través de las imágenes elegidas para constituir el cuadro comparativo, se pone de manifiesto un problema de raíz en la práctica de la investigación documental fotográfica en México: el desconocimiento de criterios de clasificación. Despojadas de su etiqueta, cada fotografía, individualmente, sería una imagen que se nos presenta llena de significado, pero desprovista de órdenes clasificatorios. En el cuadro en cuestión, la primera imagen revela el hermoso pero adusto rostro de una mujer mestiza con un rebozo de calidad y ataviada en joyas que, aunque quizás no estén hechas con piedras preciosas, sí enmarcan la figura de la mujer de manera estética y sofisticada. Sabemos que es una prostituta porque forma parte del registro sanitario del Estado de México en 1868. Sin embargo, no hay nada en el contexto del retrato que aluda a su oficio o a su condición; no hay 
índice más allá del que ella decidió marcar en su presentación, abierta, afirmativa y desafiante, ante el observador.

En la segunda fotografía tenemos a una mujer de tez blanca, robusta y vestida con un atuendo entallado, en óptimas condiciones, con guantes y capa de piel genuina y una boina que le cubre un cuarto de su rostro. Mira de frente a la cámara, aunque la toma no es cerrada, a diferencia de la primera fotografía. Su cuerpo no está enmarcado y el ángulo superior desde el que fue fotografiada incomoda a la mirada porque resulta casi una presencia esquiva en la escena. No es un retrato, a diferencia de la primera. Sin embargo, esta fotografía está registrada bajo la categoría de "prostitución" en el Sistema Nacional de Fototecas (SINAFO), sin mayor explicación sobre su catalogación. Al conocer este dato cuyo criterio desconocemos, inmediatamente opera en nuestra mirada el prejuicio y la especulación, dejando de lado toda posibilidad de definición de la imagen desde otra óptica.

La tercera imagen muestra una escena, es decir, no es un retrato propiamente, sino la representación o la recreación de una actividad en un espacio específico. Se trata de dos cuerpos semidesnudos: una mujer le practica una felación a un hombre. La primera está cubierta con ropa ligera, mientras que el personaje masculino muestra un desnudo prácticamente completo. Incluso, su rostro es visible, aunque no esté mirando fijamente a la cámara, como en el caso de los dos primeros retratos. Podría decirse que el protagonista de la fotografía son los genitales masculinos, motivo por el cual asumimos que el objetivo de la fotografía era la provocación o el consumo de un bien con un alto componente sexual. Sin embargo, esta imagen no está clasificada bajo la categoría de "prostitución". ¿Será porque la protagonista no es la mujer, sino el acto en sí mismo? Esta pregunta, si bien retórica, recoge una cuestión significativa para la clasificación de archivos en torno a temas relativos al ejercicio de la sexualidad en México, pues su sola existencia es evidencia suficiente del consumo de deseo como motor de consumo en sí mismo y como contenido del bien a consumir.

La tercera fotografía, de Juan Crisóstomo Méndez, representa un caso aparte. Sin embargo, las últimas dos fotografías de la tabla, que tipológicamente son retratos de grupo, son sumamente reveladoras tanto en su contenido, como en su clasificación. La imagen que corresponde al grupo de mujeres es una escena del Hospital Morelos, no obstante, es inquietante que sus rostros estén fuera de foco; sus identidades se encuentran para siempre resguardadas en la incógnita 
del desconocimiento documental, pero también detrás de la calidad, intencional o no, de la fotografía. Si bien se trataba de un mero registro documental sanitario y no de un retrato grupal, como lo estipula la clasificación del archivo, finalmente todas las mujeres miran fijamente a la cámara, por lo que la intención de retratarlas deviene engaño al observar el resultado.

Caso contrario es la última fotografía, un retrato grupal clasificado bajo la etiqueta de "prostitución", en el que hombres y mujeres posan en un espacio abierto, para el fotógrafo. A pesar de que en la fotografía no se encuentran indicados los nombres de los retratados, el hecho de que sus rostros estén definidos revela una intención, que es precisamente la de retratar sus identidades y capturar el momento. Sin embargo, ¿cómo saber por qué se ha clasificado esta imagen dentro de la categoría de prostitución? Inmediatamente se asume, en principio, que esa categoría alude a las mujeres, quienes ostentarían el adjetivo al que refiere dicho oficio. Sin embargo, no se tiene la certeza, en principio, de la sujeción de la escena a esa clasificación, lo cual impide el curso de una investigación objetiva e, incluso, científica sobre el fenómeno de la prostitución a través de la fotografía como fuente documental, debido al desconocimiento de los criterios clasificatorios.

Finalmente, cabe mencionar que para este proyecto hemos tomado como referencia la postura de Hans Belting respecto al lenguaje de la imagen: la pregunta no es por el qué es la imagen o qué representa, sino cómo se presenta la imagen ante el investigador, pues se trata de fotografías que fueron percibidas de una forma en el primer momento de su producción, en un espacio social específico y que llegan hasta nosotros a través de distintos medios, determinados por factores y acontecimientos puntuales en el tiempo. ${ }^{15}$

De esta manera, nos enfrentamos a un complejo cuerpo de imágenes que forman parte de diferentes acervos fotográficos y que para fines prácticos de identificación han sido clasificadas con criterios diversos, según el momento histórico. Por otra parte, su producción implica cuestiones importantes sobre el por qué y el para qué, pero más allá de eso, es el contenido de esas imágenes presentadas como fotografías lo que nos atañe. El lenguaje de las imágenes solo podrá ser decodificado mediante cuestionamientos sobre el cómo llegaron hasta nuestras manos, cómo son diferentes o similares entre sí en su forma y/o tipología,

15 “El qué que se busca en imágenes de este tipo no puede ser comprendido sin el cómo por el que se coloca como imagen o se convierte en imagen. El cómo es la comunicación genuina, la verdadera forma del lenguaje de la imagen. [...] Desde esta perspectiva, el concepto de medios, por muy grande que sea también por su importancia en otro contexto, en la actualidad no puede ser adscrito aún a un discurso establecido definitivamente" (Belting, 2007, p. 15). 
cómo se han enunciado en los archivos y, sobre todo, cómo se representan los sujetos retratados en ellas.

Estas reflexiones pretenden cuestionar las prácticas del quehacer histórico dentro del acervo, para tomar consciencia de cómo un grupo -en este caso de mujeres, trabajadoras sexuales- puede ser violentado y estigmatizado a través de algo que pareciese tan inocuo como la clasificación imágenes y archivos documentales. Visibilizar esta falta podría resultar en la reducción de lugares comunes y estereotipos, así como en una producción de conocimiento sobre los comercios del deseo mucho más precisa y rica. 


\section{Referencias}

Barthes, R. (1990). La cámara lúcida. Paidós.

Bel, J. H. C. (2003). The femme fatale in literature: the beautiful, merciless woman. In H. van Os (Ed.), Femme Fatales, $1860-1910$ (pp. 55-64). Groninger Museum/ Museum voor schone kunsten Antwerp.

Bell, S. (1994). Reading, Writing and Rewriting the Prostitute Body. Indiana University Press.

Belting, H. (2007). Antropología de la imagen. Katz.

Bernstein, E. (2014) ¿Las políticas carcelarias representan la justicia de género?

La trata de mujeres y los circuitos neoliberales del crimen, el sexo y los derechos. Debate Feminista, 50, pp. 280-320. https://doi.org/10.1016/S01889478(16)30139-6

Casanova, R. (2002) "Muñoz. La cámara participativa”. Luna Córnea, n. 24, 198-201.

Córdova, C. (2003). El Edén subvertido. Revista Alquimia, (17), 37-39.

(2005). Vintage Porn. Revista Alquimia, (23), pp. 7-16.

Debroise, Olivier. (2005). Fuga mexicana: un recorrido por la fotografía en México. Editorial Gustavo Gili.

Delgado Jordá, I. (1998). Mujeres públicas bajo el Imperio: la prostitución en la ciudad de México durante el Imperio de Maximiliano, 1864- 1867 [Tesis de maestría, El Colegio de Michoacán].

Diener, P. (1996). El perfil del artista viajero en el siglo XIX (pp. 63-86). Viajeros europeos del siglo XIX en México. Fomento Cultural Banamex.

Hallgrímsdóttir, H., Phillips, R., Benoit, C y Walby, K. (2008). Sporting Girls, Streetwalkers, and Inmates of Houses of III Repute: Media Narratives and the Historical Mutability of Prostitution Stigmas. Sociological Perspectives, 51(1), pp. 119-138.

Lamas, M. (2017). El fulgor de la noche. Comercio sexual en las calles de la Ciudad de México. Océano.

Lavrín, A. (2005). La sexualidad y las normas de la moral sexual. En A. Rubial García (coord.), Historia de la vida cotidiana en México: la ciudad barroca (II). El Colegio de México.

Lozano, L. (1999). Renovación estética en la Academia de San Carlos: el purismo de la pintura de mediados de siglo (pp. 59-16). En Arte de las Academias: Francia y México, siglos XVII-XIX. Antiguo Colegio de San Idelfonso. 
Lukacs, J. (2011). El futuro de la historia. Turner Noema.

Monroy Nasr, R. (2011). Memoria gráfica, identidad y género: imágenes de mujeres

en la posrevolución mexicana. Subversiones Memoria social y género. Ataduras y reflexiones (pp. 199-236). FONCA, CONACULTA, ENAH, INAH.

Morales, M. (2010). Los casos Lavillette y Berriozábal. Alquimia, (40), pp. 73-80.

Núñez, F. (2001). El papel del hospital en el control sanitario de la prostitución. Revista Elementos: Ciencia y cultura, 8(42), pp. 55-58.

Parent-Duchâtelet, AJ. B. (1857). De la prostitution dans la ville de Paris (3ra edición). Paris, J. B. Baillière et fils.

Reynolds, K. y Humble, N. (1993) Victorian Heroines: Representations of Femininity in Nineteenth-Century Literature and Art, New York University Press.

Salas Zamudio, S. (2011). Las postales sugestivas de los años veinte (Colección Garza Márquez). Dimensión Antropológica, 51, 153-182. https://www.revistas. inah.gob.mx/index.php/dimension/article/view/1150

Sánchez Arteche, A. (2002). El ser y el parecer. Revista de la Universidad de México, (615), pp. 31-42

Vargas, A. (1991). La casa de citas en el barrio galante. Grijalbo; Consejo Nacional para la Cultura y las Artes.

Ystehede, J. y Skilbrei, M-L. (2017). Cultural Representations of Nineteenth-Century Prostitution", Oxford Research Excuclopedia, Criminology and Criminal. https:// doi.org/10.1093/acrefore/9780190264079.013.214

\section{Archivo histórico}

Secretaría de salud. Fondo Beneficencia Pública, sección Fondos Hospitalarios, serie Hospital Morelos.

Secretaría de salud. Fondo Salud Púbica, sección Inspección Antivenérea.

Mediateca. Colección Archivo Casasola (Id. de catálogo 21443 y 36297). INAH SINAFO. http://mediateca.inah.gob.mx/

Portal de Grupo Latinoamericano de Acción/Análisis de Grupos Sexuales (GLAMSEX). https://glamsexlatam.wixsite.com/misitio 